\title{
Collective Security and State Survival in the Interstate System
}

\author{
Thomas R. Cusack \\ Science Center Berlin \\ AND \\ Richard J. Stoll \\ Rice University
}

\begin{abstract}
For hundreds of years realists have debated idealists about the nature of the interstate system and the most effective means to promote the endurance of the system and the survival of individual states. This paper uses a computer simulation called EARTH (Exploring Alternative Realpolitik Theses) to explore the viability of collective security in a realist world. The results of our experiments indicate that the practice of collective security promotes the endurance of the entire system. Our results also show that states that practice collective security principles are more likely to survive in a realist world than states that operate according to realist principles.
\end{abstract}

The antithesis of utopia and reality-a balance always swinging towards and away from equilibrium and never completely attaining it-is a fundamental antithesis revealing itself in many forms of thought. The two methods of approach-the inclination to ignore what was and what is in contemplation of what should be, and the inclination to deduce what should be from what was and what is-determine opposite attitudes towards every political problem. "It is the eternal dispute," as Albert Sorel puts it, "between those who imagine the world to suit their policy, and those who arrange their policy to suit the realities of the world." (Carr, 1946:11)

Carr's description of the study of international relations rendered just prior to the onset of World War II remains equally valid today. Driven by the most recent "lessons of history," scholars and practitioners of international relations swing back and forth, first viewing the world through the lens of realism, then through the lens of idealism. Throughout the 1980s, there was yet one more oscillation, with the early part of the period featuring a number of forays by those who argued that cooperation can occur under anarchy-that such cooperation can even be beneficial to those who practice it rather than to operate as 
"classical realism" would dictate. But as could easily have been anticipated, the end of the decade (ironically, when those with more of a policy orientation were proclaiming a "New World Order") saw a counter-attack by those who feel that cooperative behavior is not in the self-interest of states.

In fairness, there is no uniform and consensual position within realism with respect to general expectations, critical causal mechanisms, or policy prescriptions. Nonetheless, in what can be characterized as mainstream realism, there is an ample measure of optimism with respect to the prospects for system stability and individual state success (cf. Claude, 1962 and 1989). Mainstream realism, despite its recognition of the brutality of interstate politics, sees certain strong (almost natural) conditioning and equilibrating mechanisms, advocates generally a laissez-faire approach to interstate politics, and is sanguine about the prospects for both retaining system pluralism and assuring state survival. The advocates of collective security eschew this approach, arguing that what this form of realism sees as success is more oft than not failure. Systems of states do collapse and are swallowed up by hegemons (see, e.g., Watson, 1992); when this is avoided it is only narrowly so and often at great costs. States do disappear; they are conquered and absorbed by stronger, more aggressive neighbors. ${ }^{1}$ Collective security is seen as a way of avoiding these problems. By opposing aggression, even with the short-term risks and costs involved, states will enhance the stability of the system, assure that no universal empire arises, and guarantee their own long-term prosperity and survival. Realists generally ridicule this approach. It is held to be unfounded in its expectations and, ind e e d, is seen as likely to produce the outcomes it seeks to avoid.

This paper is a contribution to the continuing debate. It extends findings reported previously in Cusack (1989) and Cusack and Stoll (1990) as well as those developed by Niou and Ordeshook (1991). Using a large-scale computer simulation model of a multistate system, we are able to show that collective security practices are superior to those advocated by realists. An important point to make here is that this result holds in systems where only part of the population of states are committed to collective security strategies in the face of the remaining population of states acting in rational (by realist lights), acquisitive, and aggressive ways. The superiority is twofold: it applies to both the preservation of system pluralism (i.e., the prevention of the rise of a universal empire) and the life chances of individual states. In sum, our results undermine both the optimistic claims of some realist schools and the realist critique of collective security practices.

\section{Background: Using Computer Simulation to Evaluate the Implications of Theory in International Relations}

As mentioned above, this study employs a computer simulation model; it is called EARTH (Exploring Alternative Realpolitik Theses). The model is used here to conduct a large set of experiments intended to evaluate the relative merits of collective security and realist approaches to the management of power in interstate politics. Because of space limitations and since we offer an extensive description of it in a recent book (Cusack and Stoll, 1990), only a brief characterization is provided in this paper and that is done mainly in a later section. It should be pointed out that our simulation is an extensive elaboration of an earlier model developed by Bremer and Mihalka (1977). Recently, Duffy (1992)

\footnotetext{
${ }^{1}$ Contrast the optimistic position of Waltz (1979) with the pessimistic historical record for the nineteenth and twentieth centuries compiled by Bennett and Zitomersky (1982).
} 
has replicated our simulation and added a number of new and interesting features to it. $^{2}$

The model has been constructed with the aim of exploring the logical implications of various realist (and other) principles in interstate politics. We think it reasonable to maintain that this model captures many, if not all, of the central features that realists would ascribe to multistate systems and their workings. As with any model, it is a simplification. Nor is there any claim to have captured reality within the model. The fundamental claim is that the model is able to represent the essential dynamics of the structural and behavioral characteristics of a multistate system populated by states acting on principles that nearly any realist would find comforting. These states themselves share a limited physical space and act to protect their individual security and survival through a combination of force and cooperation.

In the model, the power of the state plays many roles and ultimately determines its ability to survive. States make choices to carry out aggression, to oppose it, to support it, or to stand to one side and accept its results. These states reap the consequences of their choices, gaining or losing power, and possibly suffering the ultimate loss, their survival. In making decisions regarding a variety of areas, for example, initiating conflict, joining an alliance, or allocating resources between internal and external purposes, states can make objective mistakes.

As we have shown elsewhere (Cusack and Stoll, 1990:19-62), there a re a significant number of contentious points within the realist literature. All too often some realists suggest that a certain factor or relationship is important in the operation of a multistate system while others deny its importance. And more frequently than not, when there is a consensus on the importance of a factor or a relationship, realists are prone to disagree on whether it promotes or undermines system stability and state survival.

\section{The Security Predicament: Realist and Idealist Prescriptions}

For many the central and defining characteristic of interstate relations is the absence of an agent that can regulate and control the behavior of states toward one another. Even in this century, where universal organizations supposedly bring states together, there is no higher authority to which states are answerable. This situation, which approaches anarchy in the view of many theorists (Morgenthau and Thompson, 1985; Waltz, 1979), leaves individual states to their own devices. Their interests, their power, the choices they make, and the actions they undertake, are a response to an environment where their security has no guarantee.

For realists, the security predicament confronting states can only be dealt with by a measured and deliberate form of policy. As noted previously, it would be misleading to suggest that realists are in accord on what that policy is and should be. But it would be fair to say that there are at least two basic approaches to this problem that are to be found in realist thought.

\footnotetext{
${ }^{2}$ One of the most dramatic differences between our version of this model and Duffy's is that he implements his in a parallel computing environment. This has allowed him to easily introduce the possibility of simultaneous wars, something excluded in our version for $\bullet$ a variety of reasons. This innovation has both theoretical and other advantages; for example, we know that while over the period 1816-1980 multiple war onset in the same year was not common, it still occurred with some notable frequency. Thus, while 48.5 percent of these years saw no war begin, and 35.8 saw one war onset, 15.7 percent saw two or more wars get underway (Small and Singer, 1982).

Duffy's results call into question some of the findings we have developed with our model But based on a review of a pre-publication version of his paper it is clear that the two implementations of the model are different in numerous areas, so a direct comparison of his findings with ours is difficult.
} 
There are many realists who are optimistic about the chances for preserving system pluralism and the sovereignty of individual states. This group divides along lines that reflect the relative degree of optimism with respect to both outcomes and the degree to which they suggest purely self-interested behavior does and should mark the state's approach to the management of power in the international system (cf. Cusack and Stol1, 1990:40-53). The more relaxed of the realists, to use Claude's (1989) term, suggest that states are and should be solely concerned with the pursuit of their own interests defined in terms of power. States can rely on the workings of the "invisible hand" of the international system to prevent any untoward outcome, either with respect to their own success and security or with respect to the preservation of systemic pluralism (Rousseau, 1970; Wesson, 1978). Action and inaction in foreign policy must be dictated by the immediate rewards that the state can anticipate. Actions born out of "emotional," ideological, social, or any other concern, are irrelevant to the proper design and implementation of policy. Failure to eschew "altruistic" motives in foreign policy can only damage the state and ultimately hinder the automatic stabilization of the system (Morgenthau and Thompson, 1985).

There is another dominant strand of realism which reflects a less relaxed and more moderately optimistic perspective on interstate politics. It is argued that the atomistic logic of a realist approach works well but that it cannot guarantee the preservation of the system (and by extension, an individual state's own longterm security) (Guicciardini, 1969; Kissinger, 1957). This approach puts forward a type of strategy that combines elements of both self-interest and concern for the community of the states as a whole. Just as many modern approaches to macroeconomics do not deny that beneficial consequences flow from the workings of markets, and yet advocate the need for intervention to prevent and remedy market failures, this approach suggests the need for individual states to be actively concerned about the international system and its members. Failure to hinder the unfettered pursuit of power by other states can disrupt the system and drive it toward the undesirable outcome of a universal empire.

Idealists reject the notion that the self-interest of individual states, even if moderated by some limited concern for the preservation of the system, can prevent catastrophic failure (cf. Claude, 1962). Order, security, and pluralism can prevail only if there is an active commitment on the part of states to rein in their own as well as others' aggressive behavior. Collective security is the idealists' codification of the power management principles that can succeed and need to be pursued if the system is to endure and individual states are to survive.

A minimum adherence to the collective security ideal requires states both to renounce the unilateral use of force for their own ends, and to come to the aid of other states that are the targets of aggression. Thus, force is sanctioned as a means to preserve the system and to punish those that would harm it, but force is not to be used for self-interested gain. Underlying these requirements are the principles of deterrence and of universality.

For idealists the principle of deterrence is no different than for the realists. Peace is preserved when potential aggressor states realize that there will be no gain from using force. An attempt to initiate the use of force against another state will be met by the immediate formation of a counter-coalition of states acting in defense of the target of the aggression. This countercoalition will possess a superior measure of power, so the aggressor will be doomed to defeat. Knowing that this will be so, no aggression will be undertaken.

The principle of universality is actually a bundle of three related assumptions. The first is that all system members will agree as to which state is the aggressor in a conflict. The second is that all will oppose the aggression. Finally, all members have the flexibility necessary to join in active opposition to the aggressor. 
Realists are highly skeptical about the validity of the assumptions of collective security (e.g., Thompson, 1953; Stromberg, 1956; Organski, 1968; Morgenthau and Thompson, 1985). In fact, some are almost contemptuous in their dismissal of collective security as a way out of the security predicament. But Downs and Iida (1992) argue that in the debate about the theoretical viability of collective security, realists have presented a series of myths about collective security. These myths involve invoking a set of very restrictive assumptions as well as conceiving of collective security in the narrowest possible manner. Since it is not plausible that states can meet these standards, realists conclude that collective security cannot work. ${ }^{3}$ Downs and Iida criticize the tendency of realists to view collective security in these narrow and rigid terms:

To demand that a system be infinitely ambitious in its aspirations or possess characteristics such as unanimity voting or universal membership before it can be considered a "real" collective security system is no more sensible in a security context than it would be in an economic context. (Downs and Iida, 1992:1)

Downs and Iida go on to show how in an economic context, a series of less restrictive assumptions could (and would) be substituted, leading to a less extreme, but by no means implausible or ineffective, version of collective security. Two examples will illustrate how Downs and Iida believe the concept of collective security can be removed from the closed logical box in which it is placed by the realists. One common criticism of collective security by realists is that in any particular situation, states will have varying assessments of the degree of threat, and this lack of consensus will prevent the successful functioning of a collective security system. Downs and Iida propose that threat perception is likely to vary as a function of distance from the threat. This suggests that a regional collective security system may be able to function successfully (Downs and Iida, 1992:6). ${ }^{4}$

Downs and Iida also criticize the realist argument that a collective security system can only operate successfully if the world is so perfect that collective security is not needed (1992:10-12; this argument is made by Morgenthau and Thompson, 1985). They point out that if this logic were correct, then the European Economic Community could never have gotten started. Clearly, to initiate the EC it was necessary for the member states to cede some authority to the supranational entity. But it was not necessary for all states to cede all authority to initiate the EC. This process could take place over time. Similarly, they argue, a partial collective security system could be established, provide a positive benefit, ${ }^{5}$ and then grow through time.

In sum, realists believe that collective security cannot operate successfully because states either will not follow its tenets, or will suffer severely-perhaps fatally-if they do. Further, the partial operation of collective security will only serve to increase the destruction of states. States will take action that serves to manage power in the system only if it is in their own self-interest. But if this is how states behave, then we are not witnessing collective security, but practices firmly rooted in realism. Advocates of collective security believe that failure to act directly to contain aggression and manage power in the system will ultimately result in the collapse of the system. Furthermore, collective security $\mathrm{c}$ an have benefits even if it is practiced by fewer than all the states in the system. Finally, it is not necessary to view collective security in the narrow terms that most realists prefer. A broader, less restrictive set of assumptions can be substituted that would make collective security a more plausible conception.

\footnotetext{
${ }^{3}$ Betts ( 1992) is the most recent effort along these lines.

${ }^{4}$ In our simulation (discussed below), those states that make their decisions according to collective security principles essentially operate in a regional fashion

${ }^{5}$ Morgenthau and Thompson (1985:455) even argue that if collective security operates with less than ideal perfection, it will exacerbate the problems of the system. They believe that a partially operating system will fail to stop an aggressor, and result in an inevitable war.
} 


\section{EARTH: A Computer Simulation of a Realist World}

Like many scholars of international relations, we believe that for too long the study of realism has suffered because of our inability to explicitly articulate and investigate its tenets. To be sure, part of the difficulty lies in the multiple meanings that have been attached to the concept. In the previous section, we sketched out a portion of the debate within the realist community (see Cusack and Stoll, 1990:19-62 for an in-depth discussion of the various strains of realist thought).

But even if we settle on a particular meaning, we have additional problems. We need to be able to construct a clear and explicit representation of our ideas, so that we can closely examine the consequences of our assumptions. One alternative to building an explicit representation which has been used by some is game theory; recent examples of this approach are Niou and Ordeshook (1991) and Bueno de Mesquita and Lalman (1992). Game the ory has a rich tradition and allows us to use the powerful tool of mathematical logic to aid in unraveling the consequences of assumptions. But this theoretical power is purchased at a price. Some inkling of this price is conveyed by the following admission contained in a recent game-theoretic investigation of a question very similar to that addressed here:

\footnotetext{
Realist-neoliberal debates, then, are readily formalized [using game theory], but we should not delude ourselves into believing that we have overcome the hardest problems. First, our model does not take account of investment and endogenous resources growth. Second, we ignore the costs of conflict. Finally, our m od e l ignores uncertainty and misperception. (Niou and Ordeshook, 1991:510)
}

As will be seen, our simulation deals with all three of these matters and more, and does so in a large system of states where long-term dynamics are represented. Thus, we believe that computer simulation allows us to model a more complex system over an extended period of time in a more dynamic fashion than is possible using game theory. Clearly all of this comes at a price. Instead of a single analytic solution, we must undertake a large number of experiments with the simulation. Consequently, one can only speak in terms of the central tendencies of our results. But this is a price worth paying for the advantages we have outlined. At the least, it can be argued that the simulation approach can complement the game-theoretic approach; the weaknesses of one approach are the strengths of the other. With this background in mind, we turn to a discussion of our simulation.

In order to build the model, we have relied heavily on our study of the realist literature. Unfortunately, as we alluded to in the beginning of this section, we do not believe that the writings of realists fit together into a single, coherent theoretical statement. Nevertheless, we have distilled what we believe are the main features of this body of work. Some of these features are widely, almost universally, accepted by realist writers. These are used to define the main properties of the model. The rest of the features that we have extracted from the literature have been the subject of contention between various realist writers. The most frequently mentioned of these features have been incorporated into the model as parameters. In this way, we can alter the impact of each of these parameters on the basic relationships in the model, and create a variety of "worlds" which are represented in the writings of various realists. 
Given the lack of consensus in the realist literature, the process of validating this model is not simple. We believe that the validation process involves three steps. First, the face validity of the model's components and programmed relationships can be assessed. In the description of the model and the parameters below, we have provided a brief discussion of the realist literature from which we drew our ideas to justify our choices for the model. Second, the plausibility of the results of a set of runs of the model can be assessed. Given a correctly working model, the results must follow from the assumptions, but an evaluation of the results can aid in assessing whether or not the initial choices made in the construction of the model were reasonable. We provide discussion of the results for this purpose. Finally, the results of a set of runs of the model can be subject to empirical study. This provides a third way to validate the model. Although we do not attempt to empirically validate the findings of this study, we have done so with previous studies using this simulation, and have found that the empirical results correspond to the simulated ones (Cusack and Stoll, 1991).

We now provide a basic overview of the phases within the model and the principal processes inside each of these phases. Figure 1 displays the basic phases of the simulation. In the next section, the variety of foreign policy orientations that can be assigned to states in the model system will be discussed. It is these different orientations that are the focus of our experiments on the impact of collective security on system endurance and state survival.

Initialization. The artificial system we use consists of ninety-eight hexagonal- shaped states arranged in seven rows and fourteen columns. A variety of parameters are initialized before each run of the model begins. Some of the more important of these parameters are: the cost states pay to fight wars, the amount of reparations that losing states must pay to winners after a war, and a parameter governing the relationship between the power ratio of the two sides and victory in war. There are many additional parameters that may be assigned (see Cusack and Sto11, 1990:63-94). The simulation allows for the possibility of civil war within the borders of states, the possibility of wars ending in ties, and for the two sides in a war to pay disproportionate costs to fight the war. Even the initial size of the system can be changed, from a two-hexagon system, all the way up to a 6400 -state system (eighty by eighty states).

Given the parameters that define the system, each state is randomly assigned a set of characteristics: an amount of power, an ability to estimate its own power, an ability to estimate the power of other states, and an internal growth rate for power, as well as several variables that determine how much effort a state will devote to retaining previously acquired territories and thereby act as insurance against the onset of a civil war and the dissolution of empire (these latter are not relevant to the experiments discussed in this paper). Most important for our concerns, states may be assigned one of several different foreign policy orientations; these are discussed in the next section.

The individual state characteristics were selected because of their prominence in the realist literature. A state's power is obviously a critical component in a realist world; some, in fact, would argue that international politics is essentially a struggle for power (Morgenthau and Thompson, 1985). The importance of power estimation is noted by traditional scholars such as Gulick (1955) and Mattingly (1955); indeed, Hawtrey (1952) argues that the balance of power is flawed because of the errors that are inevitably made by states in power estimation. Internal growth is not mentioned by all realists, but is considered to be of crucial importance by some (Fay, 1948; Organski, 1968). Finally, the necessity of devoting state resources internally to guard against the outbreak of internal conflict is mentioned by scholars both ancient (Machiavelli, 1961 [1514]) and modern 


\section{Initialization}

set system parameters

set state parameters<smiles>CCCCCCCC</smiles>

\section{Civil War}

(optional)

determine If onset;

If war, determine results:

rebellion succeeds or falls,

costs, disintegration

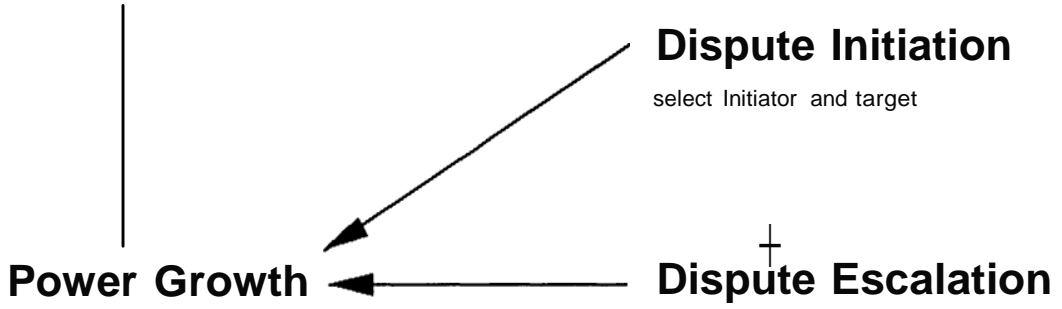

adjust power levels

allocate resources

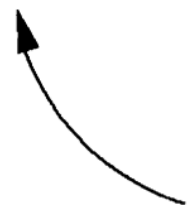

War

target and Initiator seek allies

Initiator Is deterred or chases war

determine results:

decisive or Indecisive outcome,

costs, reparations,

loss of territory,

possible elimination of state

\section{End of Run}

If universal empire

or reach Itsratlon limit

FIG. 1. Basic sequence of phases in EARTH.

(Kennedy, 1987). While there is little unanimity among scholars in the realist tradition, we believe that the characteristics with which we endow states are generally considered to be important, if not central.

Civil War. The possibility of civil war occurrence is an optional element in the model. If this option is selected, a calculation is performed in each iteration to determine if civil war might occur. If so, all multi-territorial states are checked. The probability of an individual state experiencing a civil war is a function of the degree to which that state underpays the maintenance cost necessary to control its empire. If it is calculated that a state will experience a civil war, the number of pieces of territory that revolt is determined stochastically. Given that 
number, the territories that are most costly to maintain are assigned to the secessionist group. It should be noted that pieces of territory are costly to maintain due to one or more of the following conditions: (1) the piece of territory is powerful, (2) the piece of territory has only recently been acquired by the state, (3) the piece of territory is distant from the core of the state. After identifying the secessionists, the outcome of the civil war is calculated. Victory is a function of the power ratio of the two sides. If the rebellion fails, the state remains intact, but all pieces of territory suffer a loss of power due to the costs of fighting the war. If the rebellion succeeds, all parties to the war pay the costs of fighting, and the state disintegrates, with the rebellious units forming one or more new states.

Dispute Initiation. If, as in the present case, there is no possibility of civil wars, iteration begins with the selection of a state to initiate a dispute. ${ }^{6}$ In all configurations except a system that is initially populated entirely by rational states, the probability of a state being selected is proportional to its share of the total power in the system (the conflict proneness of powerful states is noted by Bremer, 1980, and Eberwien, 1982). ${ }^{7}$ The state selected as initiator examines the states on its borders. If it finds a state over which it has an advantage, it initiates a dispute by threatening the state (if there is more than one such state on its borders, it selects the state over which it has the greatest advantage). If no state can be found, the simulation moves to the power growth phas e of the iteration. Note that the calculations of states in this phase, and all others described below, are subject to error. As will be described later as well, the choice processes of the rational states are somewhat different.

Dispute Escalation. The escalation phase represents a series of moves on the parts of the initiator, the target, and third parties. The outcome here is the ultimate choice by the initiator to press its aggression to war or to back down. The escalation phase can contain up to three rounds of alliance formation, with the first and the third conducted by the target, and the second conducted by the initiator. ${ }^{8}$ The program flow is identical for each round. The state considering the building of an alliance calculates whether it has an advantage over its opponent. If so, it does not seek allies. If the state calculates that the opponent has more power, it seeks allies. Allies must meet two conditions. First, any ally must be contiguous to the opponent. Second, if there are several possible sets

\footnotetext{
${ }^{6}$ The model assumes that there is a clear and identifiable initiator of a dispute. While the historical record is clearly replete with charges and counter-charges with regard to who was an aggressor, it does not seem overly simplistic (nor historically inaccurate) to assume that there can be clarity with respect to the identity of the actor who has made the first threat to use violence or has been the first to actually employ it (see Gochman and Maoz, 1984). Within the model a basic notion is that states that have an objectively good chance of acquiring power to the disadvantage of others and to their own benefit will have a greater chance of engaging in aggression than those that do not. This is certainly concordant with the point made by many with respect to a central tenet of realism: the aim of politics is to gain power (cf. Hamilton, 1956; Wolfers, 1962; Keohane, 1983; Morgenthau and Thompson, 1985; Wagner, 1986).

${ }^{7}$ If the system is initialized to consist entirely of rational states, the procedure is different. For each state, the expected value of fighting each of its neighbors is calculated. The highest positive expected utility for each state is summed, and each state's probability of being selected for dispute initiation is equal to its proportion of the sum of the positive utilities.

${ }^{8}$ The importance of seeking allies is stressed by many realists and is especially prominent in the work of Gulick (1955) and Morgenthau (Morgenthau and Thompson, 1985). In the model alliances are treated as transient and temporary matters of convenience, which is in keeping with the realist tradition. Thus, they endure for one iteration of the model and thereafter lapse. In effect, the flexibility in commitments that realists treat as both natural and necessary is captured here. One might note that historically even those alliances that do endure for long periods of time are notoriously unreliable (Sabrosky, 1980).
} 
of allies, the alliance-seeking state tries to build a minimum winning coalition. Once the potential allies have been identified, each is requested to join the coalition. Each potential ally makes an independent decision to join or abstain from the coalition. A potential ally calculates whether or not, given that it joins the coalition, the coalition will be larger than the opponent's coalition. If so, it agrees to join; if not, it declines the offer.

A few qualifications to this description should be noted. First, the calculations made by states using rational decision making are a little different and are described below. Second, if the target of the dispute is unable to find allies in its first phase, the initiating state immediately opts for war. Third, should an initiator seek to build a counter-alliance and fail, it ends the dispute without going to war.

War. If a war occurs, all parties pay a cost (which is a function of the relative power relationship) for fighting the war. The outcome of the war is a complex function of the actual power ratio between the initiating side and target side; a user-specified parameter controls the relationship between the power ratio and the probability of victory. ${ }^{9}$ Once the winning side is determined, the losing side must pay reparations. A proportion of the power of each loser is collected, and distributed to the members of the winning coalition in proportion to the amount of power each contributed to the coalition. The leader of the losing side (the original initiator or target of the dispute) must pay an additional cost; it must give up one or more territories. This pool of lost territory is distributed to the members on the winning side according to each member's share of the total power of the coalition. Given the discreteness of the territorial units, the result can be a very "lumpy" set of payoffs.

Power Adjustment. In the final phase of an iteration, the power of each state is increased by its internal growth rate. The remaining states in the system make decisions as to how much of their power will be devoted to the internal control of the territories they have conquered. If the simulation reaches a user-set iteration limit (1000 in the experiments for this paper), or if a single state controls all of the territory, the run ends. If neither of these conditions hold, the simulation moves to the beginning of the next iteration. ${ }^{10}$

\section{External Policy Orientation of States}

The model has been constructed in ways that permit one to explore a variety of important themes in the realist literature. Central to this is the allowance for a variety of foreign policy orientations by states. Currently, four different orientations can be represented. Two of these orientations are based on the assumption that states behave in an exclusively self-interested fashion, and two assume that states possess at least some degree of concern about other states in the system. Table 1 displays a summary of the differences between the four orientations.

The primitive power seeking orientation was the power management and

\footnotetext{
${ }^{9}$ The tend ency for the stronger side to win wars is well documented; see, e.g., Rosen (1972) and Ca nnizzo (1980).

${ }^{10}$ To reiterate, the set of phases described above (outside of the initialization phase) transpire in one iteration. Implicitly we treat each iteration as a distinct period of time and the summation of iterations as meaningful. For example, 200 successive iterations are equal to two temporally contiguous sets of 100 adjoining iterations in the same run. A state that survived through 200 iterations of the model would be considered to have achieved a superior performance to one that had survived for only I 00 iterations.
} 
TABLE 1. Characteristics of different external policy orientations.

\begin{tabular}{|c|c|c|c|c|}
\hline \multirow[b]{2}{*}{ Decision } & \multicolumn{4}{|c|}{ State Type } \\
\hline & $\begin{array}{c}\text { Primitive Power } \\
\text { Seeker }\end{array}$ & $\begin{array}{l}\text { Power } \\
\text { Balancer }\end{array}$ & Rational & $\begin{array}{l}\text { Collective } \\
\text { Security }\end{array}$ \\
\hline $\begin{array}{l}\text { Potential Initiator } \\
\text { Initiate dispute }\end{array}$ & $\begin{array}{l}\text { if more powerful } \\
\text { than neighbor }\end{array}$ & $\begin{array}{l}\text { if more powerful } \\
\text { than neighbor }\end{array}$ & $\begin{array}{l}\text { if positive } \\
\text { expected utility }\end{array}$ & $\begin{array}{l}\text { never } \\
\text { initiate }\end{array}$ \\
\hline Select target & $\begin{array}{l}\text { weakest } \\
\text { neighbor }\end{array}$ & $\begin{array}{l}\text { weakest } \\
\text { neighbor }\end{array}$ & $\begin{array}{l}\text { largest positive } \\
\text { expected utility }\end{array}$ & select no target \\
\hline Ideal Alliance & $\begin{array}{l}\text { minimum win- } \\
\text { ning coalition }\end{array}$ & $\begin{array}{l}\text { minimum win- } \\
\text { ning coalition }\end{array}$ & $\begin{array}{l}\text { largest positive } \\
\text { expected utility }\end{array}$ & $\begin{array}{l}\text { minimum win- } \\
\text { ning coalition }\end{array}$ \\
\hline $\begin{array}{l}\text { 3rd Party } \\
\text { Join offensive } \\
\text { alliance }\end{array}$ & $\begin{array}{l}\text { if more powerful } \\
\text { than other } \\
\text { alliance }\end{array}$ & $\begin{array}{l}\text { never } \\
\text { join }\end{array}$ & $\begin{array}{l}\text { if positive } \\
\text { expected utility }\end{array}$ & $\begin{array}{l}\text { never } \\
\text { join }\end{array}$ \\
\hline $\begin{array}{l}\text { Join defensive } \\
\text { alliance }\end{array}$ & $\begin{array}{l}\text { if more powerful } \\
\text { than other } \\
\text { alliance }\end{array}$ & $\begin{array}{l}\text { always } \\
\text { join }\end{array}$ & $\begin{array}{l}\text { if positive } \\
\text { expected utility }\end{array}$ & $\begin{array}{l}\text { always } \\
\text { join }\end{array}$ \\
\hline
\end{tabular}

decision making style implemented for states in the precursor simulation developed by Bremer and Mihalka (1977). It is much as its name suggests. In essence, a state satisfices in its pursuit of power. Whenever a primitive pow e r seeker has an opportunity to engage in conflict (either as a dispute initiator or as an alliance partner), it makes a simple calculation. It estimates the power of the two sides. If this assessment indicates that its side will be the larger one, it initiates (or joins) the conflict; otherwise it does not. This type of simple calculation is consistent with the ideas of Waltz (1979), who argues that rationality is not a requirement for state calculations. It is also consistent with the advice of Frederick the Great:

The wisest policy is to wait for the right moment, to see what is the situation in which you find yourself and then to profit from it so far as you can. (Frederick the Great, 1992 [1768]:162)

Some realists would agree that states act out of self-interest, but would resist the notion that they operate with a focus so narrow as that described for primitive power seekers. Instead, these realists believe that states are more sophisticated in their calculations. States are rational in their pursuit of power (Riker, 1962; Bueno de Mesquita, 1981; Morgenthau and Thompson, 1985; Niou and Ordeshook, 1991; Bueno de Mesquita and Lalman, 1992). Rather than basing decisions on the calculation of the probability of winning, these states use expected value calculations, comparing the anticipated gains or losses from joining a conflict. If these states calculate that participation in a conflict (even if they will be on the victorious side) will not produce positive expected utility, they will not take part. If the expected utility calculation produces a positive value, rational states take part in the conflict.

The final two foreign policy orientations are based on the presumption that states can be motivated by more than their own self-interest. States can also have a stake in the management of power within the system. Of course, this does not mean that states must forego all elements of self-interest. This mixture of motivations is embodied in a power balancing foreign policy orientation of the realist approach (Claude, 1962; Crowe, 1971; Sheehan, 1989). Faced with an 
opportunity to initiate a conflict, power balancers use the same procedure as primitive power seekers. Thus, a power balancer will initiate a conflict if it calculates that it can win. But faced with an ongoing conflict, power balancers act to protect the integrity of the system. If they are sought as an alliance partner by the initiating side in a dispute, they never join. But irrespective of power calculations, power balancers always join the target side in a dispute if asked.

The final foreign policy orientation of states is that of collective security. This orientation has its roots in the idealist tradition in international relations (Claude, 1962). Collective security states perceive a significant stake in the management of power in the system, and pursue power management even at the expense of their own short-term self-interest. In the words of Wolfers (1962), theirs a re goals of self-abnegation. Collective security states never initiate a dispute, nor do they ever join the initiating side of a dispute. Collective security states always join the target side of a dispute if asked. ${ }^{11}$ This orientation is captured in the following quote:

\begin{abstract}
Every Power in Europe is a member of a Group, and even if the issue in question does not oblige the others to share in the hostilities to which it may give rise, they cannot afford without an effort to see their partner preoccupied, weakened by a struggle, and perhaps defeated ... the meaning of our principle is clear. There ought to be no change in the status quo, which means the acquisition by any Power of rights over another State, however backward or weak, without the consent of the general body of civilized opinion. (Brailsford, 1992 [1914]:456-
\end{abstract} 457)

These four types of states reflect a wide range of foreign policy orientations. By varying the initial mixture of these orientations, we can create a wide variety of political "worlds." This flexibility allows us the ability to explore a broad set of questions and assertions about international politics.

\title{
The Experiments: Design and Rationale
}

The object of this paper is to explore the implications of alternative foreign policy orientations in terms of their impacts on overall system performance and individual state survival chances. The model we introduced in the previous sections allows us to configure the initial population of a multistate system in ways that combine different external orientations for the state members of the system. Recall that three realist orientations can be represented and that an additional one, based on the collective security principles drawn from the idealist approach, can also be portrayed. In the simulation studies reported here, we have experimented with systems marked by varying compositions of state types.

Foreign policy by itself need not be a sufficient determinant of either outcome of interest. External forces operating on states, that is, structural elements, and

\footnotetext{
${ }^{11}$ Given the nature of the system being modeled and the principles governing the behavior of this type of state, the form of collective security policy being portrayed comes close to the variant Haas (1955) labeled "permissive enforcement." In effect, no organization of states is directing its members to undertake collective security actions. Rather, individual members of the system are acting on behalf of a principle and are not doing so in concert.

Also, this is a localized, or regional, form of collective security. The limited ability of states to project power across geographical space in this world, in combination with the relative scarcity of states committed to such a policy, will ensure that it is not a universal system. Under most conditions as well, there will rarely be a single major power or even a limited concert of such powers that could play the role of "world policeman" in the system. No extraordinary abilities are being attributed to the form of collective security arrangement being represented. It is indeed a relatively weak form, particularly in comparison with the kinds of caricatures realists frequently draw of collective security.
} 
characteristics of states other than their foreign policies may influence system performance and state success. Thus, a comprehensive assessment of these types of foreign policies needs to take into account potentially important environmental conditions within which states operate as well as significant state characteristics. We have designed our studies in such a way as to control for a number of these. Our selection of factors is justified by the importance attributed to them by the realist literature.

In previous work (Cusack, 1989; Cusack and Stoll, 1990:137-182) we have conducted various studies that address these questions. Some central findings in these studies are related to the question of the relative superiority of realist versus idealist strategies and the question of the superiority of rational versus satisficing decision making styles within a realist approach. With respect to the first, we found that collective security strategies are superior to two realist strategies, the selfish but primitive power seeking approach, and the more moderate power balancing strategy. The relative presence of states committed to collective security principles was found to greatly enhance the durability of the system, both in terms of the likelihood that it would retain its pluralistic character and in terms of the length of time it would take to destroy pluralism should that destruction occur. In addition, contrary to realist expectations, it was found that states that practiced collective security were ecologically superior to states following these realist strategies.

In terms of the question of the relative efficacy of rational choice processes, it was found that the presence of this type of decision making style within the system wherein only realist strategies were being pursued by states lent itself to the preservation of pluralism. Furthermore, the survival chances of such states were greater than those employing the more primitive decision principles that still conform to the realist approach.

Here we will present new results based upon an extensive set of experiments wherein we have, for the first time, populated the system with mixes of sophisticated realists (i.e., the rational states) and states conforming to the idealist practice of collective security.

Let us now turn to the design of this new set of experiments. In total, 3240 experiments were conducted for the new study. These experiments were systematically varied in terms of (a) the composition of the system in terms of the numbers of collective security states as opposed to states following realist practices and using rational decision making styles; and (b) five elements that characterize the structure and workings of the system, including the distribution of power, variable growth rates, the degree to which inaccuracy and error pervade power assessments, the costliness of wars, and the restraint practiced by victors in war. In addition, because the model relies upon stochastic processes, each system configuration experiment was run two times with each replication using a different seed for the random number generator.

Since our central concern is whether realist or idealist strategies are superior, we chose to conduct a large set of experiments where the initial population of the systems varies significantly in terms of the relative presence of the two types of states therein. The expectation here is that if one strategy or the other influences the fate of the system and/or the state, then there should be a systematic effect linked to the relative composition of the system and these outcomes. Thus, for example, by varying the number of states in the system that employ collective security principles, it should be possible to detect whether or not (and to what degree) the relative presence of these states helps (per the idealists) or hinders (per the realists) the preservation of system pluralism. In turn, we can also explore the realist position that collective security states are ecologically inferior to states guided by realist principles. 
For many realists, the absence of a universal commitment to collective security principles entails an absolute certainty of failure for this strategy and dire consequences for the system. If this expectation holds, then regardless of how few or how many collective security states we introduce into the system, as long as some states are not committed to collective security, we could expect that system endurance and state survival chances would be reduced.

In this set of experiments ten groups are constructed with each group varying in terms of the mix of states in the system. These range from systems where purely realist strategies are being followed, i.e., the system contains ninety-eight states employing a realist approach to external relations, all the way to system configurations where only a small minority of the states in the system, i.e., ten states, employ such a strategy, while the remainder practice a collective security approach. Thus, the grouping with the configuration that most nearly conforms to an ideal realist world has no states employing a collective security strategy, the next grouping has ninety following a realist strategy and eight engaged in collective security practices, the next has eighty realist states and eighteen collective security states, and so on up to the configuration with ten states following the realist approach and eighty-eight pursuing collective security.

The second dimension defining the design is based upon the need to consider the potential importance of other factors that might influence the dynamics of the system. Here we draw upon the realist literature and certain critical debates therein which we have discussed in detail elsewhere (Cusack and Stoll, 1990:96107).

The importance of the ability to estimate power is an area of debate among realists. For example, Gulick (1955) argues that the evaluation of intelligence about the system's other members is important. On the other hand, Haas (1953) posits that only a rough estimate of power by states is necessary for the successful perpetuation of the system. The degree of inaccuracy of power assessment is controlled by a single parameter. This parameter, the Power Estimation Error, can be set to allow for a wide variability in states' abilities to assess power, or, alternatively, to have most states estimate power accurately.

Most writers feel that the distribution of power has a large impact on the dynamics of the system. Nevertheless, some see it as irrelevant. For example, Hawtrey (1952) argues that no distribution of power can overcome the tendency of the system to balance, but this is a minority view. Amongst those who see it as important, however, there is a division on whether an even or an uneven distribution promotes peace. This is the familiar parity-and-peace versus disparity-and-peace argument which echoed through the literature in the 1960s and early 1970s (Singer, Bremer, and Stuckey, 1972). The impact of Power Distribution is captured in the model by varying the standard deviation for the initial power distribution in the system.

While power is obviously of central concern to most, if not nearly all realist writers, one system facet has received scattered attention. This is the question of differential growth rates. Some realists are rightfully accused of ignoring the potential importance of this factor by others who see it as central to the dynamics of the interstate system (cf. Fay, 1948; Organski, 1968). However, there are others who attend to this question and conclude that it really plays no major role (e.g., von Gentz, 1970 [1806]). The Variable Power Growth parameter can be set to ensure that internal power growth is equal across all states, or to allow for some states to grow at a faster rate than others.

Most realists argue that if warfare is destructive, this lessens the chances of system endurance as well as state survival. Toynbee (1954) believes costly wars can undermine not only state survival, but also the endurance of a system of states. But others argue that the prospect of fighting destructive wars (wars using nuclear weapons, for example) will serve to deter any state from seeking 
to engage in one (Bueno de Mesquita and Riker, 1982; Waltz, 1990). The impact of the destructiveness of war is controlled by the War Cost Maximum parameter, which is the proportion of its power that a state must pay to participate in a war, controlling for the relative power of the two sides in the war.

Many realists believe that extracting too much from the losers will increase the chances of a state's destruction and ultimately the viability of the system as a multistate entity. Typically, this belief was embodied in policy advice such as Fenelon's (1975 [1700]), who said that it was never wise to "reduce your enemy too low." Other examples of this position are Kissinger's (1957) praise of Metternich and Castlereagh for reestablishing the position and stature of France immediately after the end of the Napoleonic Wars, and Kaplan's (1957) model of a balance of power system that explicitly rules out the destruction of an "essential national actor." The impact of this factor is controlled by varying the level of Reparations, the proportion of power that is transferred from the losing side to the winning side at the end of a war.

These five factors then serve as "control variables" in our design. In the case of four of them, i.e., power estimation error, the distribution of power, the cost of war, and reparations, we chose to employ three different parametric values that imply a low, medium, or high level of each. Thus, with a low parameter setting for estimation error, states generally would be relatively accurate in their estimation of power situations, while with higher values they would be more inaccurate. A low value on the power distribution factor implies a relatively even distribution of power within the system, while a higher value would entail greater inequality. A low value on the war cost parameter makes war a relatively cheap undertaking, while higher values lead to greater levels of destruction for all participants. The reparations parameter with a low value implies that victorious states are relatively generous in their demands from defeated states. Higher values mean that they show less restraint in their extractions from the losers. Finally, in the case of the fifth control variable, we employ only two alternatives. In one, we impose the constraint of equal growth, that is, all states in the system enjoy the same growth rate. In the second, variation in growth rates across the states in the system is introduced. The parameter values that define this set of experiments are detailed in Table 2.

The analyses in later sections draw on the results from this new set of experiments. What distinguishes this new set of analyses from our previous work on collective security is the mix of state types that populate the simulated systems. The two previously conducted sets of analyses contained either (a) only primitive power seeking states or (b) varying mixes of primitive power seekers, power balancers, and collective security practitioners. Both of these sets of experiments have been described elsewhere (Cusack, 1989; Cusack and Stoll, 1990:137-182). Since this new set of runs contains mixtures of collective security practitioners and states that employ expected utility decision making rules, this set will be referred to as the CSEU runs.

The next two sections report the results of the experiments. We first examine the impacts of the population configurations and control factors on syste m endurance. Following that, we turn to evidence bearing on the question of state survival.

\section{System Endurance}

The discussion now turns to an analysis of the impact of collective security practices on multistate system endurance. To provide some sense of the ability of the system to retain its multistate character, we begin by reporting some basic 
TABLE 2. Parameters for the CSEV runs.

\begin{tabular}{|c|c|c|}
\hline Parameter & Description & Values \\
\hline Power Estimation Error & $\begin{array}{l}\text { The standard deviation for } \\
\text { power estimation error. }\end{array}$ & $10,20,30$ \\
\hline Power Distribution & $\begin{array}{l}\text { The standard deviation for the } \\
\text { initial power distribution in the } \\
\text { system. }\end{array}$ & $.1, .3, .6$ \\
\hline War Cost Maximum & $\begin{array}{l}\text { The proportion of a state's } \\
\text { power that is lost by } \\
\text { participating in a war. }\end{array}$ & $.05, .1, .2$ \\
\hline Reparations & $\begin{array}{l}\text { The proportion of a losing } \\
\text { state's power that is transferred } \\
\text { to the victors in the war. }\end{array}$ & $.1, .2, .3$ \\
\hline Power Growth Rate Range & $\begin{array}{l}\text { The standard deviation for } \\
\text { power growth rates across states. }\end{array}$ & $0, .5$ \\
\hline Number of Collective Security States & $\begin{array}{l}\text { Number of states at initialization } \\
\text { that use collective security } \\
\text { power management. }\end{array}$ & $\begin{array}{l}0,8,18,28, \\
38,48,58,68 \\
78,88\end{array}$ \\
\hline Number of Rational States & $\begin{array}{l}\text { Number of states at initialization } \\
\text { that calculate expected utility of } \\
\text { initiating or joining a conflict. }\end{array}$ & $\begin{array}{l}98,90,80,70, \\
60,50,40,30, \\
20,10\end{array}$ \\
\hline Number of Iterations & $\begin{array}{l}\text { Barring the emergence of a } \\
\text { universal empire, the number of } \\
\text { iterations in a run. }\end{array}$ & 1,000 \\
\hline
\end{tabular}

descriptive statistics: the proportion of runs that end as multistate systems, the average number of iterations in a run, and the average number of states in the system at iteration 1000, reported both for all runs as well as only those runs that retain their multistate character. The final measure provides information on the degree of pluralism that exists in systems that endured.

Over 40 percent of the CSEU runs retain their multistate character. The average run lasts about 628 iterations and the average number of states surviving out of the original ninety-eight is thirty. The CSEU systems that do endure are quite populous at the termination of the experiment; they contained an average of sixty-eight states.

How powerful an effect on system endurance is exerted by the presence of collective security states? One answer to this question can be seen in the data displayed in Figure 2. There we have plotted the observed average endurance rates for the nine different subsets of these runs that contain collective security states. We can observe that the endurance rates vary systematically with the number of states committed to collective security. There is, indeed, an indication of a nonlinear relationship. At lower levels, the increase in collective security type states modestly lowers the endurance rate. Thereafter, as the relative size of this sub-population increases, it begins to sharply increase the system endurance rate. Does this apparently beneficial relationship hold when we control for other influences? To answer this question we next present some multivariate analyses that allow us to better assess the impact of collective security states on system endurance when taking into account the effects of other forces.

In Table 3 we report the results of a probit analysis that assesses the effects of a variety of factors on the probability of system endurance. Included in the 


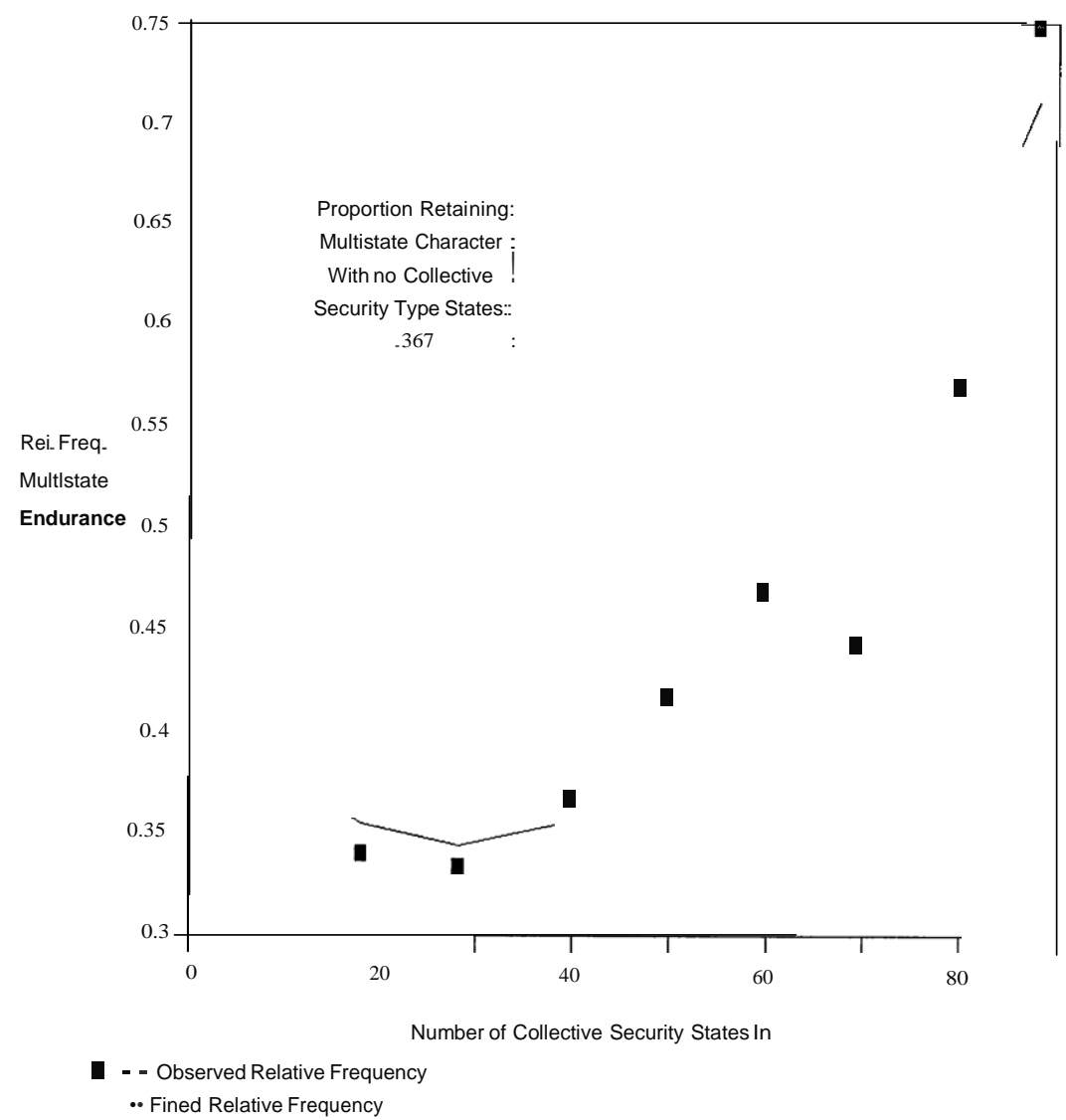

FIG. 2. Presence of states committed to collective security and likelihood of system preservation.

specification are the control variables described previously as well as measures tapping the composition of the system's population. Turning to the results we see that the degree of miscalculation in power assessments that mark the actors in the system has a strong impact on the chances of the system remaining pluralistic. The greater the variability in power estimation error across states, the less the chance of the system avoiding empire. The initial distribution of power has a negative impact. The price paid to participate in war (the war cost maximum) has a positive effect on system endurance. If wars are cheap to fight, the system is less likely to avoid empires. Large levels of reparations (payments from the losers of wars to the victors) have a negative impact on system survival. Finally, the impact of the variability in power growth rates is significant, and strongly negative, with greater variability leading to a decreased chance of system endurance.

Turning to our experimental variable, the table shows that the presence of states using collective security practices has a strong impact on system endurance. As with the results from our earlier work on collective security, the more widespread the practice of collective security, the greater the likelihood of the system retaining its pluralistic character.

The coefficients from the probit analyses are not directly interpretable. One can get a feel for the relative effects of the number of collective security states by generating some predicted probabilities for system endurance on the basis 
TABLE 3. Bases of multistate system endurance (probit analysis).

\begin{tabular}{lc}
\multicolumn{1}{c}{ Variable } & Coefficient \\
\hline Constant & .73 \\
Power Estimation Error & $(9.34)$ \\
& -.04 \\
Power Distribution & $(-15.82)$ \\
& -.41 \\
War Cost Maximum & $(-3.68)$ \\
& 5.29 \\
Reparations & $(14.22)$ \\
& -2.67 \\
Power Growth Rate Range & $(-9.86)$ \\
& -1.15 \\
Number of Collective Security States & $(-12.29)$ \\
& .01 \\
N & $(9.99)$ \\
Pet. Correct Pred. & 3240 \\
Log-Likelihood & 70 \\
Restricted Log-Likelihood & -1982.3 \\
X2 (df) & -2365.7 \\
(prob.) & $766.77(6)$ \\
\hline
\end{tabular}

t-statistics in parentheses under coefficients.

TABLE 4. Selected predicted values from probit analysis to estimate effects of collective security states on system endurance as a multistate entity.

\begin{tabular}{cc}
\hline $\begin{array}{c}\text { Number of Collective } \\
\text { Security States }\end{array}$ & Predicted Probability \\
\hline 0 & .398 \\
25 & .477 \\
50 & .557 \\
75 & .634 \\
\hline
\end{tabular}

of the estimated parameters. To calculate the predicted probabilities for comparisons, the middle value of each control variable was used. Note that in the case of the variability in growth rate parameter, the lower of the two values was used. With these parameter values fixed, the predicted values from each probit equation are generated by assuming that the number of initial collective security states is $0,25,50$, and 75 . These predicted probabilities are displayed in Table 4. Note that there were no CSEU runs in which all ninety-eight states used collective security. Finally, one should remember that the values in the table were derived from the fitted equations, and therefore are based on the assumption that the equations are an accurate representation of the processes at work in the model.

Table 4 shows that, contrary to the expectations of some realists (but in line with the thinking of Downs and Iida, 1992), if collective security principles are 
practiced by as few as one-quarter of the states in the system, it can have a discernable effect on the chances of the system retaining its multistate character. As well, the effect of increasing the proportion of states using collective security practices is roughly linear. The predicted probability rises about. 08 for every quarter of the system that practices collective security. ${ }^{12}$

The final statistical analysis at the system level uses the Tobit technique to estimate the effects of the same set of factors on the number of iterations the system endures as a multistate entity. This provides another perspective on the impact of collective security practices on the durability of the system since the dependent variable is a more finely grained measure than the endurance term, a variable that records simply success or failure to remain pluralistic. Table 5 displays the results from the Tobit analysis. Power estimation error continues to have a modest negative impact on the number of iterations a system endures as a multistate entity. The initial power distribution also has a moderate positive impact on system endurance. The war cost maximum has a very strong positive effect on endurance. Reparations has a moderate positive effect, and the power growth rate range has a strong negative impact on system endurance. The presence of states with collective security policies has a positive impact on the length of system endurance. Each additional state committed to collective security present at the onset of a run increases system endurance by about four iterations.

To assess the impact of collective security states on the length of system endurance, Table 6 uses the Tobit results to predict the number of iterations systems will endure. For all variables except the variability in power growth rates

\footnotetext{
12 This effect does not persist beyond the three-quarters mark. If all the states in the system practice collective security, no wars will occur and the probability of the system retaining its multistate character is 1.0.
} 
TABLE 5. Bases of multistate system duration (Tobit analysis).

\begin{tabular}{lc}
\hline \multicolumn{1}{c}{ Variable } & Coefficient \\
\hline Constant & 166.39 \\
& $(8.55)$ \\
Power Estimation Error & -2.31 \\
& $(-3.57)$ \\
Power Distribution & 53.26 \\
War Cost Maximum & $(1.99)$ \\
& 2379.87 \\
Reparations & $(27.28)$ \\
Power Growth Rate Range & 250.22 \\
& $(3.87)$ \\
Number of Collective Security States & -187.38 \\
& $(-8.38)$ \\
& 4.36 \\
Nog-Likelihood & $(22.45)$ \\
OLS R2 & 321.724 \\
\hline
\end{tabular}

t-statistics in parentheses under coefficients. 
TABLE 6. Selected predicted values from Tobit analysis

to estimate effects of collective security states on number of iterations system endures as a multistate entity.

\begin{tabular}{cc}
\hline $\begin{array}{c}\text { Number of Collective } \\
\text { Security States }\end{array}$ & \\
\hline 0 & Expected Duration \\
\hline 25 & 524 \\
50 & 533 \\
75 & 642 \\
\hline
\end{tabular}

and the number of power balancing states, the middle parameter value is used. For these two variables, the values are set to zero. Of course, the impact of the number of collective security states can be ascertained by examining the coefficient for that variable, but Table 6 simplifies the process. As with the predicted probabilities from the probit analyses, the table contains predictions that go beyond the range of the variables in the data set, and these predictions should be treated with some caution. The results here suggest that the $\mathrm{impact}$ of introducing collective security practices is substantial. Increasing the number of collective security states from 0 to 50 produces approximately a 50 percent increase in the length of system endurance.

\section{State Survival}

We now turn to the question of state survival. Both realists and idealists see in the strategies they advocate a benefit not only for the system but also for those who would practice these strategies. In turn, they suggest that those states that rely on the alternative strategy not only do damage to the community of states, but hurt themselves as well. While we have seen above that collective security practices appear to be socially beneficial, there are grounds, at least from the realist perspective, to believe that in performing a socially useful function, states that practice collective security will only expose themselves to greater risk than they need to and in the long run lower their own chances of survival within the system. As noted above, however, factors beyond the foreign policy orientation of a state may have an impact on its survival. To allow us to make a more direct comparison of the effect on state survival of collective security relative to other types of foreign policy orientation, we include a number of system and state level variables in the analysis that follows.

Before we discuss the variables to be included in our analysis, the sampling procedures used to generate the data employed need to be discussed. For an analysis at the state level, a tremendous amount of information is available. Across the 3240 runs conducted for the analyses, there exist at least 317,520 individual state histories. ${ }^{13}$ It is neither practical nor desirable to analyze such a mountain of data. To reduce the task to manageable proportions, a sampling procedure was used. Approximately one percent of the runs were sampled. The procedure for selecting runs involved assigning a random number from a

\footnotetext{
${ }^{13}$ Note that it is possible inside the model that a new state can enter the system after the initial period. This occurs because the loss of territory by a defeated state in a war may result in its being split into two parts. One of these separated sets of territories is then treated as a new and independent state.
} 
uniform distribution (ranging from 0 to 1 ) to each run, then selecting all runs for which the random number was less than or equal to .01. All states from these selected runs constitute the sample. The result is a total of 3827 cases.

To begin, we include all the variables from the system level analysis. This is done in order to ascertain whether state survival is affected by systemic factors, independent of the particular characteristics of the individual state. Since our reasoning for the inclusion of each system level variable was stated above, we will not repeat it here. But by way of illustration, we offer the following example. Suppose that indeed the presence of large numbers of states that practice collective security principles increases system endurance. If that were to be true, then all states, regardless of their particular circumstances, would be expected to survive a longer period of time than in a system with just a few states practicing collective security. Thus, we would want to separate out such a system level effect from state level characteristics.

In addition to these contextual factors, it is also necessary to control for a number of state level characteristics. These include such traits as the relative power of the state, its capacities in terms of accurate power assessments, and its geographical location, all critical elements in the view of realist thought.

In a realist system of multistate politics, power is an important commodity. There is a good deal of agreement that powerful states are more likely to survive and prosper (Blainey, 1973). That aside, relatively large amounts of power, however, maytempt states to an overactive foreign policy, leading them to frequently engage in foreign conflicts and wars (Bremer, 1980). Thus, relative power may be conducive to excessive taking of risky adventures, thereby lowering a state's survival chances. To control for the impact of relative power, we introduce into the analysis a variable tapping each state's Initial Share of System Power.

In light of the importance attributed to power capabilities by most theorists, it follows that, in a system where choices by each and every state are contingent on their own and others' power, the ability to accurately assess power should play a role in the success or failure of a state. Tocapture these effects, we introduce two measures, Error in Estimating One's Own Power, and Error in Estimating Other States' Power.

Interstate politics is played out in the confines of physical space. The location of a state within a multistate system may provide it with advantages or disadvantages over other states in the competition to survive and prevail. To control for this influence we also introduce a measure of a state's Geographic Position. This variable represents the degree of centrality to the geographic core of the system. Low values indicate that the state is in the center of the system, while high values indicate that the state is on the periphery. The most straightforward expectation here is that the closer to the center of the system, the more potential opponents for a state and the lower its chances of survival (Blainey, 1973). The advantages of the peripheral position are often attributed to the paucity of potential predators and the difficulties other states have in projecting power to such distant regions (Boulding, 1962; Dehio, 1962; Collins, 1978).

The broadest set of expectations about how the external orientation of a state affects its survival chances is related to whether one takes a realist or an idealist perspective. Realists would clearly favor the rational orientation and expect that those states misguided enough to base their foreign policies on collective security principles would have the least chance of surviving. The opposite expectation can be attributed to the idealists.

Table 7 provides an overview of the relative success of the two different types of external orientations. The first row of figures provides aggregate rates of survival for the different types of states across all the sampled experiments 


\begin{tabular}{|c|c|c|}
\hline & \multicolumn{2}{|c|}{ State Type } \\
\hline & Rational & Collective Security \\
\hline \multicolumn{3}{|l|}{ Overall Survival Rates } \\
\hline (1) All runs & .28 & .36 \\
\hline (2) System endured & .60 & .80 \\
\hline \multicolumn{3}{|l|}{ Survival Rates by Number of CS } \\
\hline \multicolumn{3}{|l|}{ States in System } \\
\hline (3) No CS in system & .16 & \\
\hline (4) Small number of CS & .16 & .22 \\
\hline (5) Medium number of CS & .25 & .32 \\
\hline (6) Large number of CS & .47 & .54 \\
\hline \multicolumn{3}{|l|}{ Survival Rates by Number of CS } \\
\hline \multicolumn{3}{|l|}{ States in System, System Endured } \\
\hline (7) No CS in system & .42 & \\
\hline (8) Small number of CS & .42 & .62 \\
\hline (9) Medium number of CS & .56 & .77 \\
\hline (10) Large number of CS & .76 & .92 \\
\hline
\end{tabular}

Small number is $1-33$, medium number is 34-66, large number is over 66 .

regardless of whether the system endured or not. We can clearly see that the best performance is by states that practice collective security principles .

Rows 3 through 6 and 7 through 10 provide further information on survival rates. In 3 through 6 one sees the overall survival rates in situations wherein the proportions of collective security states in the system's initial population differ. Parallel to this, in rows 7 through 10 are breakdowns in survival rates for systems that retained their pluralistic character. The overall tendencies are similar and so we will focus on the latter (i.e., 7 through 10). Once again, states committed to collective security have the best survival rates. In addition, it is clear that the rational states benefit significantly, as indicated by their improved chances of survival, when the numbers of collective security states in the initial population of the system are increased.

In Table 8 we report the results of a Tobit analysis to account for the number of iterations a state survives. ${ }^{14}$ We turn first to an examination of the system level control variables. The negative impact of the power distribution term suggests that more uneven distributions of power in the system lessen the life expectancy of individual states. Parallel to this is the negative sign on the variability of power growth coefficient. This captures the effects of variability across the system in growth rates and suggests that such variation reduces the expected lifespan of individual states. The large positive effect of the war cost maximum implies that cheap wars (wars with a low cost) shorten the expected life of individual states. The lack of restraint in the system, as reflected in the level of reparations transferred from defeated states to those on the victorious side, also reduces the life expectancy of individual states.

The effects of the state level control variables are consistent with some realists' expectations. Thus, power does seem to improve the chances of a state to survive,

\footnotetext{
${ }^{14}$ As in our previous work (Cusack and Stoll, 1990), we also analyze the impact of these same factors on state survival to at least iteration 100, and on state survival to iteration 1000 . The results of these two analyses are generally consistent with the Tobit analysis predicting the number of iterations that a state survives, so the y will not be reported here. These additional results are available from the authors.
} 
TABLE 8. Length of state survival: systemic and state determinants (Tobit analysis).

\begin{tabular}{|c|c|}
\hline Variable & Coefficient \\
\hline Constant & $\begin{array}{l}291.67 \\
(6.73)\end{array}$ \\
\hline $\begin{array}{l}\text { State Level Variables } \\
\text { Share of system power }\end{array}$ & $\begin{array}{r}13.61 \\
(1.10)\end{array}$ \\
\hline Error rate estimating own power & $\begin{array}{c}-14.45 \\
(-.71)\end{array}$ \\
\hline Error rate estimating others' power & $\begin{array}{l}67.21 \\
(3.39)\end{array}$ \\
\hline Geographic position & $\begin{array}{l}-.06 \\
(-.49)\end{array}$ \\
\hline Collective security state & $\begin{array}{l}90.79 \\
(8.19)\end{array}$ \\
\hline $\begin{array}{l}\text { System Level Variables } \\
\text { Power estimation error }\end{array}$ & $\begin{array}{l}-2.75 \\
(-3.98)\end{array}$ \\
\hline Power distribution & $\begin{array}{l}-305.32 \\
(-11.30)\end{array}$ \\
\hline War cost maximum & $\begin{array}{c}525.07 \\
(6.01)\end{array}$ \\
\hline Reparations & $\begin{array}{l}-744.79 \\
(-11.55)\end{array}$ \\
\hline Power growth rate range & $\begin{array}{l}-84.19 \\
(-3.84)\end{array}$ \\
\hline \multirow[t]{2}{*}{ Number of collective security states } & $\begin{array}{c}6.77 \\
(27.69)\end{array}$ \\
\hline & $\begin{array}{c}298.221 \\
(87.47)\end{array}$ \\
\hline $\mathrm{N}$ & 3827 \\
\hline Log-Likelihood & -27230 \\
\hline OLS $\mathrm{R}^{2}$ & .33 \\
\hline
\end{tabular}

!-statistics in parentheses under coefficients.

albeit only slightly. Power assessment propensities that reflect the tendency toward "worst case" analysis appear to enhance a state's ability to survive: underestimating one's own power, and overestimating the power of others increases the length of time a state survives. Geographic position has no discernable impact on state survival.

Consistent with the results reported above, the presence of collective security states in the system extends the lifespan of individual states within the system. Most important, we see that states practicing collective security have a tendency to survive far longer than states employing other approaches to foreign policy.

As with the system level findings, we present a set of predicted values based on the analyses of Table 8 as well as from the probit analyses predicting survival to iteration 100 and to iteration 1000. In Table 9, the mean value for all variables (except state type dummy variables) is used to assess the survival chances of the typical state of a given type. 
TABLE 9. Selected predicted values from probit and Tobit analysis to estimate effects of decision making style on state survival.

\begin{tabular}{llc}
\multicolumn{1}{c}{$\begin{array}{c}\text { Measure of State } \\
\text { Survival }\end{array}$} & $\begin{array}{l}\text { State } \\
\text { Type }\end{array}$ & CSEU Runs \\
\hline Predicted Probability of Survival & EU & .914 \\
to Iteration 100 & $\mathrm{CS}$ & .972 \\
Predicted Probability of Survival & $\mathrm{EU}$ & .171 \\
to Iteration 1000 & $\mathrm{CS}$ & .242 \\
Predicted Number & $\mathrm{EU}$ & 384 \\
of Iterations & $\mathrm{CS}$ & 475 \\
\hline
\end{tabular}

For state type, EU = Expected Utility; $\mathrm{CS}=$ Collective Security.

The predictions speak for themselves. Collective security states demonstrate a superior ability to survive, whether this is measured as survival through the initial stages of the system, as survival to the end of a run, or in terms of expected number of iterations. States that follow the tenets of collective security clearly outperform states using the rational external policy orientation.

\section{Conclusion}

EARTH is a model that simulates a stark realist world, a world in which conflict is frequent and often deadly. States rise or fall dependent on their own resources, the choices they make, and the willingness of other states tojoin them in temporary alliances. We have introduced into this world several alternative policy styles to observe their effects on system endurance and state survival. It is these two concerns that have been at the heart of realism.

The systemic consequences of different types of state strategies appear to beprofound. Contrary to realist thought, a unanimous commitment to collective security principles on the part of the system is not required for such practices to have beneficial consequences. Instead, there is evidence to suggest not that it is an "all or nothing" game as many realists would have it, but rather that the beneficial consequences in terms of the preservation of system pluralism are directly proportional to the relative frequency with which states practice collective security principles.

The findings reported at the state level are of particular interest. They accord with the results of Axelrod's (1984) seminal work on cooperation among egoists. In the present case our results suggest that cooperative behavior directed toward defending other states from aggression benefits not only the system as a whole, but also those individual states that follow such a strategy. Indeed, our results suggest that practitioners of collective security are ecologically superior to states following other, more self-interested and clearly realist strategies. It is indeed intriguing that in an experimental setting radically different from Axelrod's, a conclusion similar to his can be produced.

This study was undertaken with three purposes in mind. The first has been to refine and extend results that we had found previously about the viability of collective security in a realist world. The findings from both our old and new experiments are consistent and, within the confines of the EARTH simulation, compelling. The presence of states using the collective security strategy is conducive to the preservation of the multistate character of the system. States that practice collective security can expect to fare better than states adhering to any 
of a number of realist strategies. This conclusion needs to be explored further, both at the theoretical level and the empirical one.

The second purpose was to show that computer simulation can be a valuable tool to help us explore the implications of our theorizing. It is particularly useful for grappling with the long-term consequences of large systems of states that interact. Deducing the consequences of a relatively simple model-such as EARTH-can become almost impossible without using the tool of simulation. We have found it to be very useful and suggest that others might as well.

The third and broader purpose has been to continue our exploration of the theoretical soundness and utility of the realist approach to the study of international politics. Just as there are cycles in fashion and politics, so too, as Carr once pointed out, are there cycles in the fashionable approach to the study of politics. In the study of international politics the popularity of realism has ebbed and flowed. Recently, under the guise of "neo-realism," it has once again enjoyed a degree of popularity. There clearly are sociological, economic, and political sources of this variation in the approach's acceptance by the scholarly and political communities. There are, however, few signs that realism, even in its most recent guise, has gained ground on the basis of a convincing display of theoretical rigor or empirical accuracy. Efforts to formalize central elements of the realist approach and to evaluate major points of contention therein play an important role. In this way realism's intrinsic strengths and weaknesses, as well as its utility relative to other approaches, might receive more serious attention than fashion at any time dictates.

\section{References}

AxELROD, R. (1984) The Evolution of Cooperation. New York: Basic Books.

BENNETT, R. W., AND J. ZJTOMERSKY (1982) "The Delineation of International Diplomatic Systems, 1816-1970: The Correlates of War Project's System Reconstructed." In On Making Use of History: Research and Reflections from Lund, edited by J.Zitomersky. Lund: Esselt Studium.

BETTS, R. K. (1992) Systems for Peace or Causes of War? Collective Security, Arms Control, and the New Europe. International Security 17:5-43.

BLAINEY, G. (1973) The Causes of War. New York: Free Press.

BouLDING, K. E. (1962) Conflict and Defense: A General Theory. New York: Harper and Row. BRAILSFORD, H. N. (1992 [1914]) (from The War of Steel and Gold) In Basic Texts in International Relations, edited by E. Luard, pp. 456-460. New York: St. Martin's Press.

BREMER, S. A. (1980) "National Capabilities and War Proneness." In The Correlates of War II: Testing Some Realpolitik Models, edited by J. D. Singer, pp. 57-82. New York: Free Press.

BREMER, S. A., AND M. MIHALKA (1977) "Machiavelli in Machina: Or Politics among Hexagons." In Problems of World Modeling, edited by K. W. Deutsch et al. Boston: Ballinger.

BuENO DE MESQUITA, B. (1981) The War Trap. New Haven, CT: Yale University Press.

BuENO DE MESQUITA, B., AND D. LALMAN (1992) War and Reason: Domestic and International Imperatives. New Haven, CT: Yale University Press.

BuENO DE MESQUITA, B., AND W. H. RIKER (1982) An Assessment of the Merits of Selective Nuclear Proliferation. journal of Conflict Resolution 26:283-306.

CANNIZZO, C. A. (1980) "The Costs of Combat: Death, Duration, and Defeat." In The Correlates of War II: Testing Some Realpolitik Models, edited by J. D. Singer, pp. 233-257. New York: Free Press.

CARR, E. H. (1946) The Twenty Years' Crisis, 1919-1939: An Introduction to the Study of International Relations. New York: Harper and Row.

CLAUDE, I. (1962) Power and International Relations. New York: Random House.

CLAUDE, I. (1989) The Balance of Power Revisited. Review of International Studies 15:77-85. CoLLINS,

R. (1978) "Some Principles of Long-Term Social Change: The Territorial Power of States."

In Research in Social Movements, Conflict, and Change, vol. 1, edited by L. Kriesberg. Greenwich, CT: JAI Press. 
CROWE, SIR EYRE (1971 [1929]) "England's Foreign Policy." In Politics and the International System, edited by R. L. Pfaltzgraff, Jr., pp. 450-451. Philadelphia: J . B. Lippincott.

CusAcK, T. R. (1989) "The Management of Power in a Warring State System: An Evaluation of Balancing, Collective Securirty, and Laissez-Faire Policies." In Power in World Politics, edited by R. J. Stoll and M. D. Ward, pp. 209-226. Boulder, CO: Lynne Rienner.

CusACK, T. R., AND R. J. STOLL (1990) Exploring Realpolitik: Probing International Relations Theory with Computer Simulation. Boulder, CO: Lynne Rienner.

CusACK, T. R., AND R. J. STOLL (1991) Balancing Behavior in the Interstate System, 1816-1976. International Interactions 16:255-270.

DEHIO, L. (1962) The Precarious Balance. Translated by C. Fullman. New York: Alfred A. Knopf.

DowNs, G. W., AND K. IIDA (1992) The Theoretical Case against Collective Security. Paper presented at the 1992 Annual Meeting of the American Political Science Association, Chicago, September 3-6.

DuFFY, G. (1992) Concurrent Interstate Conflict Simulations: Testing the Effects of the Serial Assumption. Mathematical Computer Modelling 16:241-270.

EBERWEIN, W.-D. (1982) The Seduction of Power: Serious International Disputes and the Power Status of Nations. International Interactions 9:57-74.

FAY, S. B. (1948) "Balance of Power." In Encyclopaedia of the Social Sciences, vol. 1, edited by E. R. A. Seligman and A. Johnson, pp. 395-399. New York: Macmillan.

FENELON, F. (1975 [1700]) (from "Two Essays on the Balance of Power") In Theory and Practice of the Balance of Power, 1846-1914: Selected European Writings, edited by M. Wright, pp. 39-45. London: Dent.

FREDERICK THE GREAT (1992 [1768]) (from "Politisches Testament") Reprinted in Basic Texts in International Relations, edited by E. Luard, pp. 162-164. New York: St. Martin's Press.

GENTZ, F. voN (1970 [1806]) (from "Fragments upon the Present State of the Political Balance of Europe") Reprinted in The Theory of International Relations: Selected Texts from Gentili to Treitschke, edited by M. G. Forsyth et al., pp. 277-304. London: George Allen and Unwin.

GoCHMAN, C. S., AND Z. MAoz (1984) Militarized Interstate Disputes, 1816-1976: Procedures, Patterns, and Insights. journal of Conflict Resolution 28:585-615.

GuiCCIARDINI, F. (1969 [1561]) The History of Italy. Translated and edited by S. Alexander. Princeton, NJ: Princeton University Press.

GuLICK, E. V. (1955) Europe's Classical Balance of Power: A Case History of the Theory and Practice of the Great Concepts of European Statecraft. New York: W. W. Norton.

HAAs, E. (1953) The Balance of Power as a Guide to Policy-Making. journal of Politics 15:370-39.

HAAs, E. (1955) Types of Collective Security: An Examination of Operational Concepts. American Political Science Review 49:40-62.

HAMILTON, A. (1956) In A. Wolfers and L. W. Martin, The Anglo-American Tradition in Foreign Affairs: Readings from Thomas More to Woodrow Wilson, pp. 130-154. New Haven, CT: Yale University Press.

HAwTREY, R. G. (1952) Economic Aspects of Sovereignty. London: Longmans, Green.

KAPLAN, M. (1957) System and Process in International Politics. New York: John Wiley.

KENNEDY, P. (1987) The Rise and Fall of the Great Powers: Economic Change and Military Conflict from 1500 to 2000. New York: Random House.

KEOHANE, R. O. (1983) "Theory of World Politics: Structural Realism and Beyond." In Political Science: The State of the Discipline, edited by A. Finifter. Washington, DC: American Political Science Association.

KISSINGER, H. A. (1957) A World Restored: Metternich, Castlereagh, and the Problems of Peace, 18121822. Boston: Houghton Mifflin.

KuPCHAN, C. A., AND C. A. KuPCHAN (1991) Concerts, Collective Security, and the Future of Europe. International Security 16:114-161.

MACHIAVELLI, N. (1961 [1514]) The Prince. Translated by George Bull. London: Penguin.

MATTINGLY, G. (1955) Renaissance Diplomacy. London: Jonathan Cage.

MoRgENTHAU, H., AND K. W. THOMPSON (1985) Politics among Nations: The Struggle for Power and Peace, 6th edition. New York: Alfred A. Knopf.

N10u, E., AND P. C. ORDESHOOK (1991) Realism versus Neoliberalism: A Formulation. American journal of Political Science 35:481-511.

N1ou, E., P. C. ORDESHOOK, AND G. F. RosE (1991) The Balance of Power: Stability in International Systems. Cambridge: Cambridge University Press.

ORGANSKI, A. F. K. (1968) World Politics. New York: Alfred A. Knopf. 
RIKER, W. (1962) The Theory of Political Coalitions. New Haven, CT: Yale University Press.

RosEN, S. (1972) "War Power and the Willingness to Suffer." In Peace, War, and Numbers, edited by B. Russett, pp. 167-183. Beverly Hills, CA: Sage.

RousSEAU, ].-]. (1970) (excerpts from various writings) Reprinted in The Theory of International Relations: Selected Texts from Gentili to Treitschke, edited by M.G. Forsyth et al., pp. 127-180. London: George Allen and Unwin.

SABROSKY, A. (1980) "Interstate Alliances: Their Reliability and the Expansion of War." In The Correlates of War II: Testing Some Realpolitik Models, edited by]. D. Singer, pp. 161-198. New York: Free Press.

SHEEHAN, M. (1989) The Place of the Balancer in Balance of Power Theory. Review of International Studies 15:123-134.

SINGER,]. D., S. BREMER, AND]. STUCKEY (1972) "Capability Distribution, Uncertainty, and Major Power War, 1820-1965." In Peace, War, and Numbers, edited by B. Russett, pp. 19-48. Beverly Hills, CA: Sage.

SMALL, M., AND]. D. SINGER (1982) Resort to Arms: International and Civil Wars, 1816-1980. Beverly Hills, CA: Sage.

STROMBERG, R. N. (1956) The Idea of Collective Security.Journal of the History of Ideas 17:250-263.

THOMPSON, K. W. (1953) Collective Security Reexamined. American Political Science Review 47:753772.

ToYNBEE, A. J. (1954) A Study of History, vol. 9. London: Oxford University Press.

WAGNeR, R. H. (1986) The Theory of Games and the Balance of Power. World Politics 38:546-576.

WALTZ, K. (1979) Theory of International Relations. Reading, MA: Addison-Wesley.

WALTZ, K. (1990) Nuclear Myths and Political Realities. American Political Science Review 84:731746.

WATSON, A. (1992) The Evolution of International Society. London: Routledge.

WESSON, R. G. (1978) State Systems: International Pluralism, Politics, and Culture. New York: Free Press.

WIGHT, M. (1972) "The Balance of Power and International Order." In The Bases of International Order: Essays in Honour of C. A. W. Manning, edited by A. James, pp. 85-115. London: Oxford University Press.

WoLFERS, A. (1962) Discordand Collaboration: Essays on International Politics. Baltimore, MD: Johns Hopkins University Press. 